rounded by water in the condenser $F$. A current of water keeps the condenser suffieiently cool. The volatil lower chlorides of vanadium escape through the tube $J$ and are absorbed by concentrated sulfuric acid in the filter flask G. Excess of chlorine or unabsorbed gases pass out through the side aperture to a hood or drain pipe. Chlorine is obtained either by generation with a mixture of manganese dioxide, salt and sulfuric acid, or from a tank of liquid chlorine. Since the flow of chlorine need not be rapid -2 to 3 bubbles a second-the chlorine can be generated very satisfactorily. The gas passes through a wash bottle containing water, then through one containing concentrated sulfuric acid, and then into a three-necked Woulf's bottle also containing concentrated sulfuric acid. A tube dipping below the acid serves for the introduction of carbon dioxide and to trap the chlorine. To start the preparation, the air in the reaction tube and condenser is removed by passing a current of carbon dioxide for some time. Chlorine is then allowed to replace the air in the purifying apparatus. When all air has been displaced, the train is connected up and the furnace started. The heat is brought up slowly while a stream of chlorine is passed, displacing the carbon dioxide.

Fifty to IOo grams of ferro-vanadium are sufficient for a charge, since the ferric chloride formed will fill the reaction tube and may be carried over into the condenser with the vanadium tetrachloride.

In order to preserve vanadium tetrachloride indefinitly it was found best to dissolve it in carbon tetrachloride. In case any ferric chloride contaminates the vanadium tetrachloride obtained by the above method, it can easily be removed, since it is insoluble in carbon tetrachloride.

\title{
BEHAVIOR OF THE HYDRONITROGENS AND THEIR DERIVATIVES III LIQUID AMMONIA. V. ELECTROLYSIS OF A SOLUTION OF AMMONIUM TRINITRIDE IN LIQUID AMMONIA.
}

By A. W. Browne AND M. E. Holars.

Received April 14, 1913.

The electrical conductivity of hydronitric acid in aqueous solution has been determined by Ostwald, ${ }^{1}$ by Hantzsch, ${ }^{2}$ and by West. ${ }^{3}$ Hittorf ${ }^{4}$ has investigated the behavior of ammonium trinitride in aqueous solution toward the electric current. Peratoner and Oddo, ${ }^{5}$ and Szarvasy ${ }^{8}$ have electrolyzed aqueous solutions of hydronitric acid and of sodium trinitride, with a view to investigating the possible formation of poly-

' See Curtius and Radenhausen, J. prakt. Chem., [2] 43, 207 (1891).

3 Ber, 32, 3066-88 (1899), p. 3072.

${ }^{3} \mathrm{~J}$. Chem. Soc. London, 77, 705-7 (1900).

${ }^{4} Z$. physik. Chem., so, 593-620 (1892).

${ }^{5}$ Gazz. chim. ital., 25, II, I3 (1895); 30, II, 95 (1900); Chem. Zentralbl., 1895, II, 864 ; 1900, II, 660.

- J. Chem. Soc. London, 77, 603 (1900). 
meric nitrogen. With a similar end in view, a study of the behavior of a solution of potassium trinitride in anhydrous hydronitric acid toward the electric current was recently undertaken in this laboratory.? The electrolytic corrosion of various metallic anodes in aqueous solutions of hydronitric acid and of sodium trinitride has been investigated by. Turrentine. ${ }^{2}$

In the third article of the present series ${ }^{3}$ it has been shown that ammonium trinitride in liquid ammonia solution reacts toward certain metals in the sense of a general equation given by Franklin ${ }^{4}$ for the action of liquid ammonia solutions of ammonium salts upon metals: $\mathrm{M}+\mathrm{NH}_{4} \mathrm{X}=\mathrm{MX}+$ $\mathrm{NH}_{3}+\mathrm{H}$. From this viewpoint the solution of ammonium trinitride in liquid ammonia is, therefore, virtually a solution of free hydronitric acid, and affords a convenient means of studying certain of the properties of this treacherous substance in the anhydrous condition.

In the present investigation the behavior of a liquid ammmonia solution of ammonium trinitride toward the electric current has been studied. The purpose of the work has been to gain some further information concerning the chemical properties of the discharged $\mathrm{N}_{3}-$ ion, or of nascent nitrine, as the aggregate of nitrogen atoms might be termed. ${ }^{5}$

Materials Used.-The ammonia was carefully dried by distilling it through a long tube filled with sodium wire. The ammonium trinitride was prepared, as described in detail elsewhere, by bubbling dry ammonia gas through an ethereal solution of anhydrous hydronitric acid and filtering off the precipitated ammonium salt.

Apparatus.-The apparatus, which is shown in the accompanying sketch, consisted essentially of the two tubes $A$ and $B$ provided with the bulbs $D$ and $E$ and connected together near the bottom by means of the small tube $C$. Each of the larger tubes was furnished with a side tube, $V, W$, to which was attached a two-way stopcock $X, Y$. The side tubes were bent as shown in the figure in order to permit the flowing back into $A$ or $B$ of liquid ammonia that might, in an emergency, find its way into them. The larger tubes were provided with tightly fitting, paraffined corks, $H, K$, through which passed the capillary tubes $G$ and $F$, which were sealed at the lower end to electrode tubes, $12 \mathrm{~cm}$. long, and $\mathrm{I}_{1} / \mathrm{cm}$. inside diameter, and at the upper end to the two-way capillary stopcocks, $N, P$. The capillary tubes $T$ and $U$ opened into the atmosphere; while $R$ and $S$ communicated with water-jacketed Hempel gas burets filled with mercury.

'Browne and Lundell, This Journal, 3I, 435-48 (1909).

2 This Journal, 33, 803-28 (1911); see also Ibid., 34, 375, 382, 385 (1912).

${ }^{3}$ Browne and Houlehan, Ibid., 33, 1742-52 (I9II).

Ibid., 27, 820-5I (1905), p. 822.

Dennis and Browne, Ibid., 26, 577-612 (1904), p. 578.

- This Journal, 33, I742-52 (1911), p. 1743 . 
The electrodes used throughout the greater part of the work were pieces of smooth platinum foil $2 \mathrm{~cm}$. long and $0.5 \mathrm{~cm}$. wide. In certain cases the electrodes were coated with a coherent, yet fairly rough layer of platinum black, in order to ascertain whether the electrode reactions were appreciably influenced by the character of the electrode surface. In

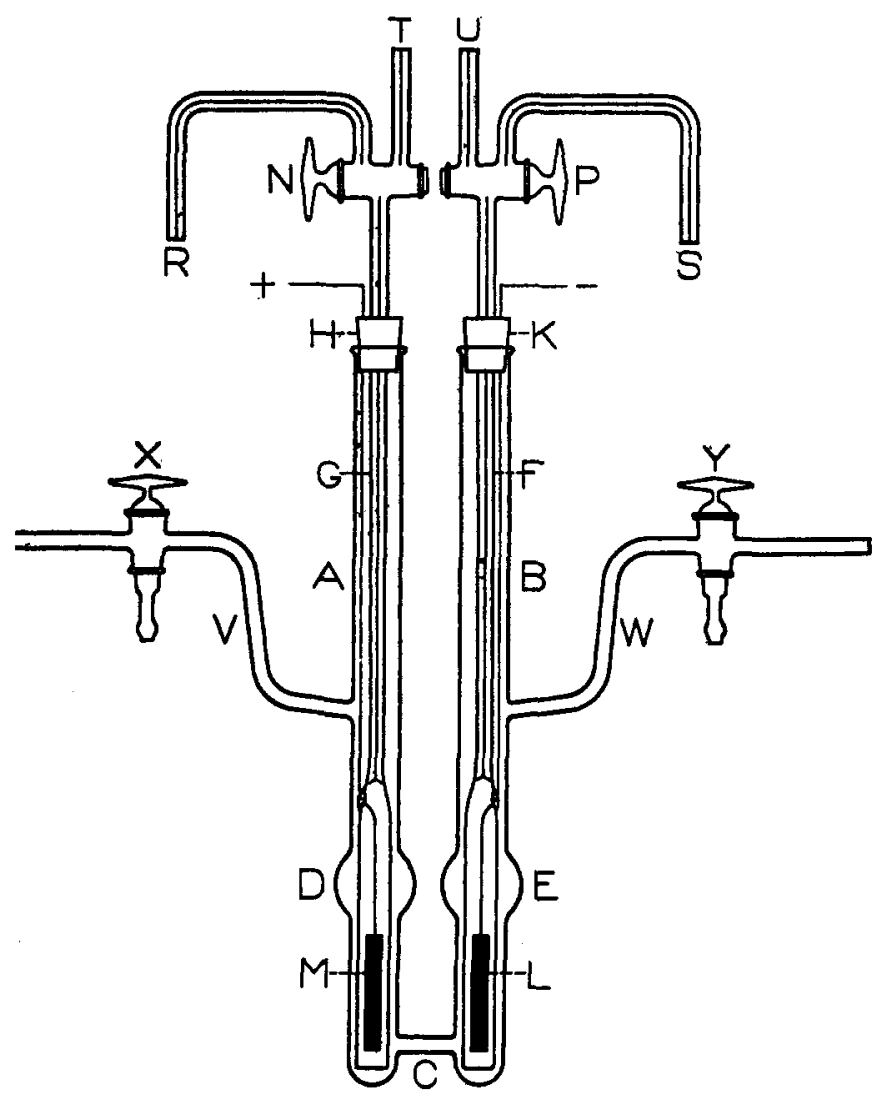

other cases an anode consisting of a short piece of smooth platinum wire of $0.3 \mathrm{~mm}$. diameter was employed, for the purpose of obtaining a relatively high current density at the anode. A graphite rod two centimeters long and two millimeters in diameter was used as anode in certain other experiments, in order to investigate still further the effect of changing the character of the electrode surface.

General Procedure.-After the cell had been thoroughly cleaned and dried, one of the electrode tubes was removed for a moment, and a weighed amount of pure, dry ammonium trinitride was introduced into the apparatus. The tube was then replaced, and a current of dry air was aspirated through the cell for a short time, after which the air was displaced 
by means of ammonia. With the aid of a vacuum beaker filled with solid carbon dioxide and alcohol, about $36 \mathrm{cc}$. of ammonia were finally condensed in the apparatus. Thorough mixture of the solution of ammonium trinitride was brought about by properly manipulating the stopcocks during the boiling of the liquid, or by bubbling dry ammonia or nitrogen gas through the liquid in various ways. The electrode tubes were filled by forcing the electrolyte, with the aid of a current of dry nitrogen gas introduced through the side tubes, up to the top of the capillary, or just below the stopcock, which during this operation was turned so as to communicate with the outer air. Unless care had been taken previously to cool the electrolyte to a temperature considerably below its boiling point, it was of course found that the liquid boiled rather vigorously when it was first brought into contact with the comparatively warm capillary tubes. By alternately opening and closing each of the stopcocks $N$ and $P$, it was found possible in a few moments to displace all air or other gases (except ammonia) from the electrode tubes. The capillary tubes $R$ and $S$ were completely filled at the outset with mercury from the Hempel burets. The electrolytic cell was connected in series with a milliammeter and with a copper coulometer on a I Io volt direct current circuit. A potential difference of from 85 to I lo volts was maintained between the electrodes of the cell throughout the greater part of the work, and the temperature was held in the neighborhood of $-67^{\circ} \mathrm{C}$. As soon as the circuit was closed, a very clearly perceptible evolution of gas took place at each electrode. After a sufficient quantity of the gas had collected to bring the level of the electrolyte down to the top of either electrode, the stopcock was carefully opened, and the gas was forced over into the buret with the aid of a current of nitrogen admitted through the stopcocks $X$ and $Y$. This operation was repeated for both anode and cathode gases until a quantity of gas sufficient for analysis had been collected in each case. Quantitative removal of the last installment of gas evolved was effected by a process similar to that by which the electrode tubes were filled with liquid at the outset, except that the gas was in this case driven over into the buret, instead of being allowed to escape into the air. The buret pinch-cocks were now closed, and the burets were disconnected from the electrolytic cell. The volume of each of the samples was first measured, and the gas was introduced into a Hempel simple mercury absorption pipet containing a $5 \%$ solution of sulfuric acid, by means of which the very considerable amount of ammonia that was carried over with the sample of gas was removed. The volume of the residual gas was carefully measured, and the sample was subsequently passed into a pipet containing alkaline pyrogallol. Very small volumes of oxygen were in general found in both anode and cathode gases, undoubtedly owing to slight leakage of air into the apparatus during the frequent manipulation of the stop- 
cocks. The percentage of hydrogen, when this gas was present, was determined by the method of absorption with palladium sponge. Small amounts of hydrogen were in some cases found in the anode gases. No evidence of the presence of hydrazine, which might theoretically have been formed by the reduction of the hydronitric acid, ${ }^{1}$ was obtained by examination of the solid left in the cell after the ammonia had completely evaporated, although in certain of the experiments, notably in Nos. I, 2 and 6, the deficit in cathode hydrogen seems to indicate that some reduction had taken place.

Details of the Experiments. - Certain of the more important details of the individual experiments are summarized in the following table.

In all of the experiments the volume of the electrolyte was made as nearly as possible equal to $36 \mathrm{cc}$. The current, although remaining fairly constant during a given experiment, varied throughout the work with change in temperature and in concentration of ammonium trinitride between 30 and 200 milliamperes. The duration of the individual experiments varied from about one-half hour to over five hours. In the first four experiments a relatively low current density was used at the anode. In Experiment 4 the solution was subjected to the action of the current for three hours and thirty-two minutes before introducing the coulometer into the circuit, or beginning to collect the electrode gases. This preliminary treatment was carried out in order to ascertain whether the nature of the electrolytic process changed after some time had elapsed. Another purpose served by this procedure was that of eliminating the possible influence of traces of impurities such as moisture, which might be expected to produce some effect, especially at the beginning of the electrolysis, and also the influence of the possible solubility of the gases in the electrolyte.

In Experiments 5, 6, 7 and 8, a relatively high current density was maintained at the anode by substituting a platinum wire for the foil previously used. This was done in the hope of facilitating the possible polymerization of the discharged $\mathrm{N}_{3}{ }^{-}$ions, with formation of the aggregate $\left(\mathrm{N}_{3}\right)_{2}$. The electrolysis proceeded in the same manner as in the previous experiments, however, with no indication that polymerization was taking place. The electrolyte did not, in any case, manifest an explosive character, nor was there any observable liberation of iodine when crystals of potassium iodide were introduced into the electrolyte in the anode tube after the gases had been collected, and the gas burets had been removed. In fact, no explosion whatever occurred throughout the entire investigation. $^{2}$ That the maintenance of a comparatively high current

${ }^{1}$ Cooke, Proc. Chem. Soc., 19, 2 I 3 (1903).

${ }^{2}$ All precautions ordinarily taken during work with the compounds of hydronitric acid were, however, observed throughout the research. See Browne and Lundell, loc. cit., p. 44 r. 


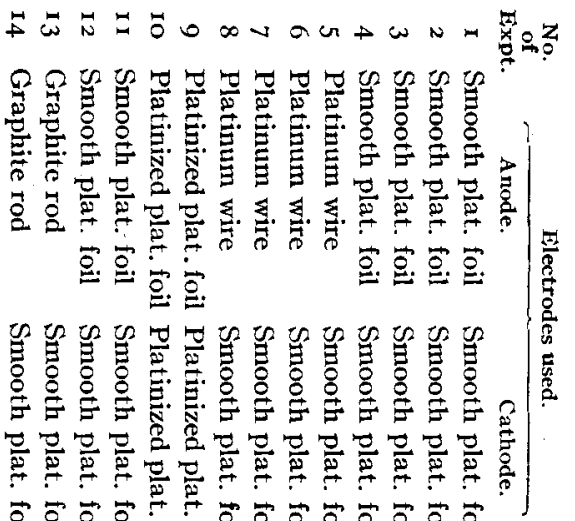

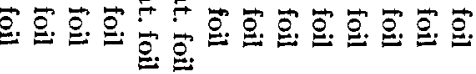

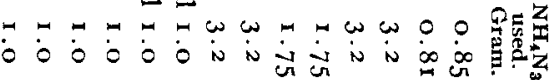

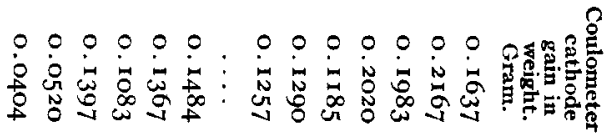

w

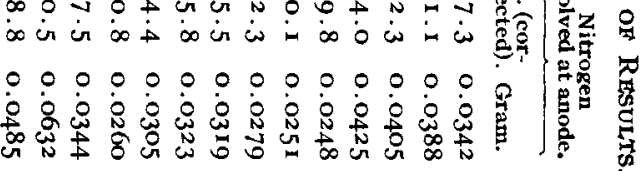

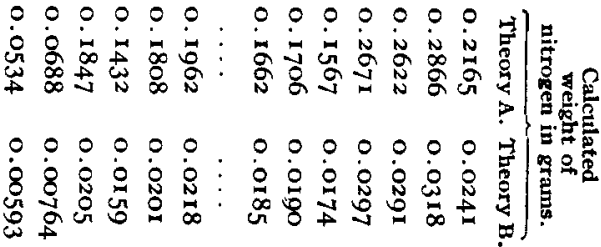

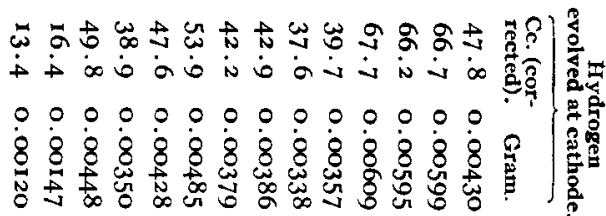

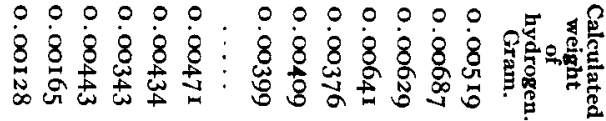

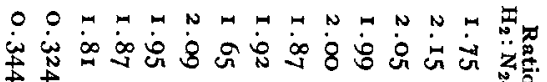


density at the anode did not effect any very profound change in the nature of the electrode reactions is moreover indicated by the results in the last column of the table. The average value of the ratio $\mathrm{H}_{2}: \mathrm{N}_{2}$ in the first four experiments is 1.99 , while the average in the next four is I.86. In Experiments 6 and 8 as in Experiment 4, the electrolyte was subjected to a preliminary treatment with the current, before the collection of the gases, and the insertion of the coulometer in the circuit. In Experiment 6 , this preliminary electrolysis was carried on for four hours and in Experiment 8 for two and three-quarters hours.

Experiments 9 and to were performed in order to test the influence of electrode surface upon the electrode reactions. The platinum electrodes were covered with a coherent and yet fairly rough coating of platinum black. . In certain of the earlier experiments it had moreover been observed that the platinum anode, after it had been used repeatedly, showed distinct signs of having undergone corrosion. This was particularly noticeable at the bottom of the electrode, where the current density was highest. In the experiments in which a platinum wire anode was used the effects of the corrosion were most clearly apparent. The wire became perceptibly shorter after it had been repeatedly used. In Experiments 9 and to the platinized platinum anode was so constructed as to be readily detachable, and was weighed before and after each experiment, in order to ascertain the extent of the corrosion. In Experiment 9 the anode lost $0.005^{8} \mathrm{gram}$, and in Experiment Io an appreciable loss was sustained, but owing to an accident the extent of the loss could not be quantitatively determined. The electrolyte gradually assumed a light yellowish tint, probably attributable to small amounts of platinum. The results obtained on analysis of the gases liberated during these experiments indicate that the platinized surface does not appreciably influence the reactions that take place at the electrode.

In Experiments $I I$ and 12 the corrosion of the platinum anode was studied under conditions substantially the same as those in the two preceding experiments, except that smooth electrodes were substituted for those with the platinized surface. The corrosion was in these cases of the same order of magnitude as in those already discussed. In Experiment II the anode lost 0.0034 gram and in experiment $12,0.0048$ gram. The electrolyte again assumed a distinctly yellow color, and a finely divided black deposit of platinum appeared on the cathode.

The use of a graphite electrode in Experiments $\mathrm{I}_{3}$ and $\mathrm{I}_{4}$ yielded results of considerable interest. The anode, which was detachable, was carefully dried and weighed at the beginning of each experiment. At the conclusion, it at first appeared to have undergone an appreciable increase in weight, but after it had been gently heated to remove occluded gases, its final weight did not differ significantly from its weight at the out- 
set. It will be observed, however, that the ratio of the volume of hydrogen to the volume of nitrogen evolved is very different from that obtained in any of the experiments in which a platinum anode was employed.

Discussion of Results Obtained.-On the assumption that ammonium trinitride when dissolved in liquid ammonia yields the hydrogen ion, ${ }^{1}$ $\mathrm{H}^{+}$, and the nitrine ion, $\mathrm{N}_{3}^{-}$, it is obvious that for each atom of copper deposited upon the coulometer cathode there should be liberated two atoms of hydrogen at the cathode and 6 atoms of nitrogen at the anode. In case no secondary reactions take place at the electrodes except the transformation of nascent nitrine into ordinary molecular nitrogen, in accordance with the equation

$$
2 \mathrm{~N}_{3}=3 \mathrm{~N}_{2} \text {, }
$$

it would seem inevitable that hydrogen should be evolved at the cathode and nitrogen at the anode in the ratio $\mathbf{I}: 3$. The theoretical weights of hydrogen, and the weights of nitrogen as listed in the column headed "Theory A" have been calculated on the basis of this supposition. From the experimental results obtained it is clear, however, that the gases were in no case evolved in a ratio even approximating this value, when platinum anodes were used. The results obtained with a graphite anode, on the other hand, agreed very closely with the theoretical ratio.

It was at first supposed that the deficit of nitrogen shown when platinum anodes were used might be attributed to the formation at the anode of a platinum trinitride. This seemed to be borne out by the corrosion of the anodes, noted in an earlier paragraph, and by the deposition of platinum upon the cathode. Even granting, however, that the platinum removed from the anode went into solution as $\operatorname{Pt}\left(\mathrm{N}_{3}\right)_{4}$, which has by no means been shown to be the case, the amounts of nitrogen thus held back in Experiments 9, II, and $\mathrm{I} 2$ would suffice merely to change the ratio $\mathrm{H}_{2}: \mathrm{N}_{2}$ to $\mathrm{r} .8 \mathrm{I}, \mathrm{I} .68$ and $\mathrm{I.62}$, respectively.

It would seem, then, that the discharged $\mathrm{N}_{3}{ }^{-}$ion, if it is not converted quantitatively into molecular nitrogen, must to some extent either (I) remain dissolved in the electrolyte, or (2) participate in some secondary reaction. That the former is not the case appears from the failure to obtain any indication of the presence of a polymeric form of nitrogen, as already mentioned. The most probable secondary reaction is the decomposition of the solvent, with regeneration of hydronitric acid, and liberation of nitrogen. ${ }^{2}$ This may be considered to occur after the discharge of the ion, in accordance with the equation

'In connection with the question as to the existence or non-existence of the "metallic" radicle $\mathrm{NH}_{4}$, see Cady, J. phys. chem., I, 707-13 (1897); Ruff, Ber., 34, 2604-7 (1901); Moissan, Compt. rend., I33, I 71-4 (I901).

2 A similar explanation has been given by Divers, to account for the phenomena observed during the electrolysis of a solution of ammonium nitrate in ammonia. See Trans. Roy. Soc. London, $163,359-77$ (1873), page 375 . 


$$
4 \mathrm{NH}_{3}+3 \mathrm{~N}_{3}=3 \mathrm{NH}_{4} \mathrm{~N}_{3}+\mathrm{N}
$$

or before the discharge, as indicated by the equation

$$
{ }_{4} \mathrm{NH}_{3}+3 \mathrm{~N}_{3}^{-}=3 \mathrm{NH}_{4} \mathrm{~N}_{3}+\mathrm{N} \equiv
$$

If the latter be the true explanation, then the negative carrier may well be the triply charged nitride ion, $\mathrm{N} \equiv$. In either case, nascent, or monatomic nitrogen should be liberated at the anode. If the reaction were to proceed quantitatively in this direction, the process would virtually be an electrolysis of ammonia, rather than of hydronitric acid, and would be comparable with the familiar electrolysis of water acidulated with sulfuric acid. It is of course conceivable that one, or two, rather than three of the $\mathrm{N}_{3}{ }^{-}$ions might act upon the molecule of ammonia, with formation of $\mathrm{NH}_{2}-$ or $\mathrm{NH}^{=}$ions, and that these might subsequently liberate $\mathrm{N} \equiv$ as before, or react among themselves, after discharge, with formation of ammonia, nitrogen, and perhaps also hydrogen. It is also possible that under proper conditions the $\mathrm{N}_{3}$ groups might replace one, two, or three hydrogen atoms of an ammonia molecule, forming $\mathrm{NH}_{2} \mathrm{~N}_{3}, \mathrm{NH}\left(\mathrm{N}_{3}\right)_{2}$, and $\mathrm{N}\left(\mathrm{N}_{3}\right)_{3}$, respectively, which would be analogous to mono-, di-, and trichloramine. The non-explosive character of the solutions and of the residual substances, however, renders the formation of such products in the present experiments rather improbable.

If the foregoing hypothesis be correct, there should be liberated at the anode one atom of nitrogen for every three $\mathrm{N}_{3}$ - ions discharged, or oneninth of the amount required for Theory $A$. In the column of the table headed Theory B are recorded the amounts called for by this second view. A comparison of the amounts of nitrogen gas actually liberated at the anode in the different experiments, with the amounts required for Theory $A$ and Theory $B$, shows that in every experiment in which platinum electrodes were used, the amount found was intermediate between the theoretical values, although decidedly closer to that of Theory $B$.

From these facts it seems reasonable to conclude that when platinum electrodes are employed some of the $\mathrm{N}_{3}-$ ions are decomposed into molecular nitrogen, but that the greater number react with ammonia sa as to regenerate ammonium trinitride and liberate nascent nitrogen. When a graphite anode is used, the first of these. reactions takes place almost quantitatively.

The liberation of nitrogen from ammonia by the action of the $\mathrm{N}_{3}-$ ion at low temperatures seems surprising in the light of the results obtained by Moissan ${ }^{1}$ during the electrolysis of ammonium chloride in liquid ammonia. Between the temperatures of $-60^{\circ}$ and $-80^{\circ}$ he found that the chlorine liberated at the anode did not decompose the ammonia, with formation of nitrogen, and did not form nitrogen trichloride, but

${ }^{1}$ Compt. rend., I33, 713-4 (Igor). 
that it would dissolve in the liquid, imparting to it a yellow color. On the assumption that this observation, as well as the hypothesis just formulated is correct, the conclusion seems inevitable that at temperatures below $-60^{\circ}$ and under the other conditions prevailing in the experiments, nascent nitrine, $\mathrm{N}_{3}$, is more active chemically than nascent chlorine. This may possibly be explained on the ground that the nascent chlorine tends at once to polymerize into less active aggregates, while $\mathrm{N}_{3}$ does not polymerize with equal readiness.

\section{Summary.}

In the present investigation it has been shown:

(I) That solutions of ammonium trinitride in liquid ammonia readily conduct the current.

(2) That with platinum electrodes of different sorts, under various conditions of concentration and of anode current density, electrolysis of the solutions results in the liberation of hydrogen at the cathode, and of nitrogen (with negligible quantities of hydrogen) at the anode, in a ratio $\mathrm{H}_{2}: \mathrm{N}_{2}$ varying from 1.65 to 2.15 (and averaging 1.93 ), instead of the ratio 0.333 to be expected in case the discharged $\mathrm{N}_{3}{ }^{-}$ion simply breaks up into molecular nitrogen.

(3) That these facts may be most readily explained by assuming that some of the $\mathrm{N}_{3}{ }^{-}$ions break up, after discharge, into molecular nitrogen, but that the greater number react with ammonia so as to regenerate ammonium trinitride and liberate (possibly nascent) nitrogen.

(4) That with a graphite anode the ratio averages 0.334 , indicating quantitative conversion of $\mathrm{N}_{3}$ into molecular nitrogen.

Cornell University, Ithaca, N. Y.

[Contribution from the Laboratory of Physical Chemistry of the University OF Illinois. PUblication No. 13.]

THE LAWS OF "CONCENTRATED" SOLUTIONS. V." PART I: THE EQUILIBRIUM BETWEEN ARSENIOUS ACID AND IODINE IN AQUEOUS SOLUTION; PART II: A GENERAL LAW FOR CHEMICAL EQUILIBRIUM IN SOLUTIONS CONTAINING IONS; PART III: THE ENERGETICS OF THE REACTION BETWEEN ARSENIOUS ACID AND IODINE.

BY EDWARD W. WASHBURN AND EARLE K. STRACHAN. Received March 29, 1913. CONTENTS.

PART I: I. Purpose of the Investigation. 2. Previous Investigations. 3. Outline of the Experimental Method. 4. Purification of Materials and Preparation of Solutions. 5. The Distribution of Iodine between Water and Carbon Tetrachloride.

${ }^{1}$ The 4 th paper of this series was published under the title, "The Electrical Conductance of Concentrated Solutions of Electrolytes," Trans. Amer. Electrochem. Soc., 21, I25 (I912). 